\title{
Designing workshops to be sociable rather than remote
}

\section{Carmen Vallis}

University of Sydney, Australia

Keywords: design workshops; co-design; learning design; online facilitation; Covid-19.

\section{The challenge}

My university has a long and proud campus tradition, so the Covid-19 lockdown response and 'pivot' to remote learning was especially stressful. Suddenly demand was high for hands-on support in educational technologies, which was exhausting for academics and support staff alike. Rapid shifts in educational policy direction and general uncertainty created extra emotional labour in terms of supporting students and each other (Sobel and Evans, 2020). Despite this, as a team, we knew we had to somehow keep educational design and pedagogy on the agenda.

Our Business Co-design team at the University of Sydney Business School facilitates workshops with academics, students, alumni, and industry professionals to invite multiple perspectives on course designs and to create curriculum change. These co-design workshops also offer academics time and space to reflect on their teaching approaches and often spark academic development. Normally, we would organise a bright airy room at a convenient time, card games as icebreakers, plenty of colourful post-it notes and pens, and food and coffee, to create a social and welcoming environment where participants feel comfortable to contribute and critique. Without our usual props, and in the middle of a pandemic, our challenge was this: how to engage large groups of people in co-design mediated by technology?

\section{The response}


Firstly, it meant thinking differently about what is normal and acknowledging that communication may be high or low quality, whether in-person or mediated by technology (Stokoe et al., 2021). Our homes were now improvised teaching and learning spaces (Williamson, Enyon and Potter, 2020). In universities we were used to categorising education into delivery modes of face-to-face, blended, or online, whereas in reality learning traverses different spaces, time zones, platforms and media, and is about learners and their environments (Fawns, 2019). Our challenge was to connect with individuals and integrate home into the workshops without intruding on private spaces or co-opting their social media spaces (Venn et al., 2020). We had to create a social experience in workshops, within the constraints of university platforms, that was not remote and not normal. What follows is an account of my perspective as a 'pracademic', as an educator, learning designer and researcher in education, working in the context of these co-design workshops (Netolicky, 2020, p.391).

'Remote' learning has connotations of being far away from the usual, preferred campus classroom; perhaps of an unemotional experience. Instead, our workshops were purposefully reframed as social events and guided by the design thinking principles of empathy and a curious and open mindset (Beligatamulla et al., 2019). From experience, we knew educators had their students' wellbeing at heart and would be influenced by evidence showing a teaching and learning strategy or tool could improve learner experience.

The preparation, planning, and research time for my first workshop was about five times as long as the event itself. However, the preparation for subsequent workshops reduced dramatically once the pattern was established. This included the following features, while also welcoming facilitator creativity and improvisation:

- A minimum of slides was designed and developed to structure the experience for group interaction.

- A detailed run sheet was written with timings and scripts with words of encouragement, and instructions when the content or transition to a new activity was complex. Text prompts for common instructions were prepared, ready to cut and paste into the chat. 
- Collaborative tools and documents were created with appropriate permissions, including online whiteboards and interaction tools such as polls, word clouds, and Q\&As.

- Group formation was considered and configured.

- The staging of activities was rehearsed. Facilitators logged on early to check audiovisual equipment, shut down unneeded applications and notifications, and open relevant files and browser tabs, ready to share.

- Mindset was important, which meant being mentally as well as physically present, hydrated, rested (ideally), and excited for the event.

\section{Recommendations}

Sometimes even the best plans go awry. At times cognitive overload caused disconnects. Between managing the unexpected and thinking about how I was communicating, pausing, and fumbling my words, while operating software, I was hyper conscious that participants were waiting and disengaging. In my concern for the operational, I sometimes forgot to involve participants in decisions about how the workshop played out. In co-design this is a critical oversight (Drain and Sanders, 2019). Also, it was challenging, and sometimes impossible to monitor all groups in private breakout rooms, so it was difficult to notice and encourage quiet participants to voice their opinions.

Few educators have help managing live learning events, even on a large scale. I aimed to manage the experience as a gracious host. When technology inevitably glitched, I called it out, laughed, and moved on. These are real moments all can relate to, and I reminded myself that participants were contending with other more serious challenges in their personal and professional lives. It also helped to let go of an authoritative, formal stance, and talk with participants as friends and equals, whether they were academics, professional colleagues, or students. In the end, learning is about memorable, personal transformation so I did include personal stories and encouraged participants to do likewise if they felt comfortable.

Workshops tended to work well when I was focused on how participants were feeling rather than my own self-doubts. Allowing time for everybody to feel welcome and present was key: for example, I grounded the experience by asking everybody to show an object 
(or choose a virtual background) and describe how it relates to the here and now. I praised all chat, ignoring typos.

Participants were appreciative. Students signalled interest in follow-up co-design workshops and sent unsolicited thanks. Another student went one step further and suggested we use this as a process for all subjects. Similarly, a business academic emailed to thank our team for making online learning 'productive'. Our team continues to design, refine, and evaluate co-design in such workshops (Vallis et al., in-press).

In summary, it helped to emphasise the human rather than the remote aspect and pedagogy over technology. As Bryant notes, we need to remember the 'humanity and ambition at the end of the Zoom chat or watching the recorded lecture' (Jandrić et al., 2020, p.1100). Our team's experience of co-design mediated by technology is that it can be both intentionally gracious and social, which can help us all to learn better.

\section{References}

Beligatamulla, G., Rieger, J., Franz, J. and Strickfaden, M. (2019) 'Making pedagogic sense of design thinking in the higher education context', Open Education Studies, 1(1), pp.91-105. https://doi.org/10.1515/edu-2019-0006.

Drain, A. and Sanders, E. B-N. (2019) 'A collaboration system model for planning and evaluating participatory design projects', International Journal of Design, 13(3), pp.39-52.

Fawns, T. (2019) 'Postdigital education in design and practice', Postdigital Science and Education, 1(1), pp.132-145. https://doi.org/10.1007/s42438-018-0021-8.

Jandrić, P., Hayes, D., Truelove, I., Levinson, P., Mayo, P., Ryberg, T., Monzó, L. D., Allen, Q., Stewart, P. A., Carr, P. R., Jackson, L., Bridges, S., Escaño, C., Grauslund, D., Mañero, J., Lukoko, H. O., Bryant, P., Fuentes-Martinez, A., Gibbons, A. and Hayes, S. (2020) 'Teaching in the age of Covid-19', Postdigital Science and Education, 2(3), pp.1069-1230. https://doi.org/10.1007/s42438-02000169-6. 
Netolicky, D. M. (2020) 'School leadership during a pandemic: navigating tensions', Journal of Professional Capital and Community, 5 (3/4), pp.391-395. https://doi.org/10.1108/JPCC-05-2020-0017.

Sobel, K. and Evans, L. (2020) 'Emotional labour, information literacy instruction, and the COVID-19 pandemic', Journal of Learning Development in Higher Education, Issue 19, December, pp.1-8. https://doi.org/10.47408/jldhe.vi19.607.

Stokoe, E., Haddington, P., Hindmarsh, J., Kohonen-Aho, L., Oittinen, T., Rintel, S. and Seuren, L. 'Is communicating in person the "gold standard"? You're asking the wrong question', Medium, 17 June 2021. Available at https://elizabethstokoe.medium.com/is-communicating-in-person-the-gold-standard-youre-askingthe-wrong-question-381a68626c10 (Accessed: 20 June 2021).

Vallis, C., Wilson, S., Tyrrell, J. and Narayan, V. (in press) 'Co-design as professional learning: pulling each other in different directions, pulling together', in Forbes, D. and Walker, R. (eds) Learning to teach online: continuing professional learning and development for tertiary teachers. Singapore: Springer Nature.

Venn, E., Park, J., Andersen, L. P. and Hejmadi, M. (2020) 'How do learning technologies impact on undergraduates' emotional and cognitive engagement with their learning?', Teaching in Higher Education, pp.1-18. https://doi.org/10.1080/13562517.2020.1863349.

Williamson, B., Eynon, R. and Potter, J. (2020) 'Pandemic politics, pedagogies and practices: digital technologies and distance education during the coronavirus emergency', Learning, Media and Technology, 45(2), pp.107-114. https://doi.org/10.1080/17439884.2020.1761641.

\section{Author details}

Carmen Vallis is a Lecturer in Educational Development. She leads co-design projects with business academics and a multidisciplinary team at the University of Sydney. Her expertise is in designing for learning with digital tools, writing, and educational research. 